\title{
Predictors of mortality among newborns admitted with perinatal asphyxia at public hospitals in Ethiopia: A Prospective cohort study
}

Samuel Dessu ( $\sim$ dessusamuel@yahoo.com )

Researchers https://orcid.org/0000-0001-9800-1076

Zinabu Dawit

Arba Minch Health Science College

Abebe Timerga

Wolkite University

Muluken Bafa

Arba Minch Health Science College

\section{Research}

Keywords: Perinatal asphyxia, Prospective study, Predictor of mortality, Southern Ethiopia

Posted Date: February 18th, 2021

DOI: https://doi.org/10.21203/rs.3.rs-184712/v1

License: (c) (i) This work is licensed under a Creative Commons Attribution 4.0 International License. Read Full License 


\section{Abstract}

\section{Introduction:}

Perinatal asphyxia is a fetus or the newborn's health problem caused; due to altered breathing or inadequate inhalation and exhalation resulting in reduced oxygen perfusion to certain body tissues and organs. Irrespective of the increased progress in health care towards newborns and implementations in reductions in under-five, infant, and neonatal mortality in the past ten years, perinatal asphyxia remains as the most common severe newborn health challenge causing a high number of mortalities and morbidity and is a major public issue.

\section{Methods}

A prospective cohort longitudinal study was implemented among the predetermined 573 samples of newborns admitted with Perinatal asphyxia at public hospitals in Southern Ethiopia from 1st March 2018 to 28th February 2020. Data entry was conducted using Epi data version 3.02 statistical software and exported to SPSS Version 25 statistical software for analysis. The perinatal survival time was determined using Kaplan Meier survival curve together with a log-rank test. Variables that had a P-values less than 0.05 in the multivariable cox proportional hazard model were declared as statistically significant predictors of mortality.

\section{Results}

The cumulative proportion of survival among the newborns admitted with perinatal asphyxia was $95.21 \%$ (95\%Cl:91.00,97.48), 92.82\% (95\% Cl:87.95,95.77), 92.02\%(95\% $\mathrm{Cl}: 86.84,95.22)$ and $90.78 \%$ (95\% Cl:84.82,94.48) at the end of first, second, third and fourth follow-up days respectively with the overall mean survival time of $6.55(95 \% \mathrm{Cl}: 6.33,6.77)$. Cord prolapse (AHR:6.5;95\%Cl:1.18,36.01), history of PIH (AHR:25.4;95\%Cl:3.68,175.0), maternal iron deficiency anemia (AHR:5.9;95\%Cl:1.19,29.5) and having convulsion of the newborn (AHR:10.23;95\%Cl:2.24,46.54) were statistically significant in multivariable cox proportional hazard model.

\section{Conclusion}

The risk of death among newborns with perinatal asphyxia was high during the early follow-up periods after admission to the hospital and the mortality risk decreased at the later follow up periods and cord prolapse, history of $\mathrm{PIH}$, maternal history of iron deficiency anemia and newborns history of convulsion were the independent predictors of mortality.

\section{Introduction}


Perinatal asphyxia is a complicated newborn health problem and applies a high contribution to the increased proportion of newborn mortality (1). It is a leading cause of morbidity and mortality in newborn babies globally, with higher case fatality rates and consequent complications in developing countries due to poor health facilities $(2,3)$. Globally, around $2,500,000$ child deaths were reported in the early 28 days of age (neonatal age). These accounts for nearly $47 \%$ of under-five mortality and $54 \%$ of all under-five deaths occur during this age in developing countries (4).

However, greater than 2/3rd of newborns can be saved through established maternal and newborn health intervention programs. Though, most of the observed deaths have occurred at home delivered newborns (5). Nearly 3.6 million (3\%) of all infants suffer from a certain level of perinatal asphyxia. Among this $840,000(23 \%)$ will die and approximately a similar proportion of newborns develop life-threatening health problems in developing countries $(6,7)$.

Globally, around $25 \%$ of all newborn mortality is caused by perinatal asphyxia (8). In Ethiopia, in the year 2015 , perinatal asphyxia contributed to $31.6 \%$ of newborn deaths, followed by prematurity and neonatal sepsis, which accounted for $21.8 \%$ and $18.5 \%$ respectively (9).

Irrespective of the increased advancements in perinatal care and implementations in reductions of underfive, infant and neonatal mortality in the past decades $(4,10,11)$, perinatal asphyxia remains a severe newborn health problem. This leads to a high number of mortality and morbidity and is a major common public health issue, commonly in developing countries like Ethiopia (12).

Even though Ethiopia reached its child mortality reduction goal 2 years earlier, the neonatal mortality rate remained high. One of the major causes of newborn deaths was intrapartum-related complications of which birth asphyxia accounts for $25 \%(13,14)$.

Moreover, a very limited number of studies were conducted in Ethiopia to identify information for intervention regarding the death due to perinatal asphyxia. Therefore; this study was planned to estimate the time to death and its predictors among newborns with perinatal asphyxia at governmental hospitals in Southern Ethiopia.

\section{Methods}

\section{Study design, setting, period and populations}

A prospective cohort longitudinal study was employed at Sawla General Hospital, Arba Minch General Hospital and Chencha district Hospital from first of March 2018 to $28^{\text {th }}$ of February 2020. Among those hospitals, over four thousand newborns were delivered per year and more than 612 newborns were admitted to the neonatal intensive care unit (NICU) at each hospital ${ }^{15}$.

Follow up was started at diagnosis of perinatal asphyxia immediately after birth for those delivered at the hospital and at admission to the hospital for those delivered from $1^{\text {st }}$ March 2018 and the follow-up 
period was closed on $28^{\text {th }}$ February 2020 . Follow-up was initiated immediately at the diagnosis of PNA and followed until seventh day of life. The follow-up was closed if the newborn was died, discharge with recovery, lost to follow-up from treatment, transferred to another institution and follow-up time ended without the event happening.

In this study, a newborn that withdrew treatment, discharged with recovery, transferred to another institution, and who did not yet develop the event at the end of the follow-up period was operationally defined as Censored. Sample size was estimated by Open Epi 3.02 statistical software using double population proportion formula in considering the assumptions; $95 \% \mathrm{Cl}, 80 \%$ power, exposed to unexposed ratio: 1, percent of unexposed with outcome (Not having history of premature rupture of membrane (PROM)): $50 \%$, percent of exposed with outcome (Having history of PROM): 62\%, AHR: 1.67 and considering $10 \%$ for non-response, the sample size became 573 . Sample size was allocated to each hospital proportionally based on the number of the admitted cases and consecutive sampling method was applied (Figure 1).

\section{Study variables}

The dependent variable was time to perinatal mortality and the independent variables were classified as socio-demographic factors (sex of the newborn, maternal age, marital status, a religion of the mother, maternal educational status, maternal occupational status, family size, place of residence, distance between home and hospital and estimated monthly income), obstetrics related characteristics (number of antenatal care (ANC) visits, gravidity, parity, number of pervaginal examinations, history of meconiumstained amniotic fluid, the onset of labor, history of antepartum hemorrhage, history of obstructed labor, history of premature rupture of membrane, history of prolonged rupture of membrane, cord prolapse, presentation of the fetus, mode of delivery and gestational age), newborn related factors (cry immediately at birth, history of convulsion or spasm and birth weight) and maternal medical related characteristics (history of PIH, maternal iron deficiency anemia, maternal diabetes mellitus, and maternal HIV status).

\section{Operational definitions}

Perinatal Asphyxia: is a diagnosis when the newborn's fifth minute APGAR score less than 7 OR complete absent respiratory effort immediately at birth.

Maternal Anemia: The hemoglobin level of a pregnant woman or early delivery mother less than $11 \mathrm{gm} / \mathrm{dl}$.

Premature rupture of the membrane: a rupture (breaking open) of the membranes (amniotic sac) before labor begins.

Prolonged rupture of membrane: a rupture of membranes lasting longer than 18-24 hours (i.e., between the time of rupture and time of delivery).

Convulsion: newborn who experience an episode of rigidity and uncontrolled jerky motions that generally last a minute or two along with altered consciousness. 


\section{Data collection procedure, quality control and analysis}

Structured checklist was used to collect the data. Data extraction tool was carefully designed to improve data quality. In addition; both data collectors and supervisors were trained. Pretest was conducted (5\% of the population). Sensitivity analysis was conducted. The maternal hemoglobin test results were obtained from a laboratory report which was prepared for this research purpose. The hemoglobin level was adjusted for altitude according to criteria set by WHO (World health organization).

Epi Data version 3.02 was used to enter the data, code the data, edit the data and clean the data. Finally, the data entered in to Epi Data were exported to SPSS version 25 for statistical analysis. The Kaplan Meier survival curve, together with a log-rank test, was used to estimate the survival time and the time which had higher risk of death. Variables that had a p-value $<0.05$ in bivariate analysis were considered as candidates for multivariable analysis and variables which had a $p$-value $<0.05$ in multivariable cox proportional hazard model were considered as statistically significant.

\section{Ethical consideration}

Ethical clearance was obtained from Arba Minch University, college of medicine and health sciences ethical review board. All participants provided an informed consent. Mothers were informed about the objective and significance of the study prior to the data collection. Appropriate measures were applied to ensure the confidentiality of the data.

\section{Results}

\section{Socio-demographic characteristics}

In this study a total of 573 newborns were involved, of which $351(61.3 \%)$ of them were males. In considering maternal age maximum of the mothers $(70.7 \%)$ were categorized as under $20-34$ years of age and the smallest amount (13.6\%) were mothers having age less than 20 years old. Regarding the marital status and religious status of the mothers, $51(8.9 \%)$ of the mothers were never married and the maximum number of the mothers (43.5\%) were orthodox in their religion followed by protestants (31.9\%).

Equal numbers of mothers were both unable to read and write and college and above, each accounted for $11 \%$ of the whole mothers. Among the mothers of the newborns, $273(47.6 \%), 192(33.5 \%)$, and $108(18.8 \%)$ of the mothers had less than four, four to six, and greater than six family sizes. More than three fourths $(76.4 \%)$ of the mothers were urban residents and around $93(16.2 \%)$ of the mothers had more than $50 \mathrm{~km}$ distance between their home and the hospital. Among the dead newborns, $33.3 \%$ of mothers were urban residents and $66.7 \%$ were rural residents.

In considering the maternal khat chewing and alcohol consumption habits, $18(7.9 \%)$ of the mothers had a habit of khat chewing and similar proportions $(7.9 \%)$ of the mothers had a habit of alcohol consumption. In addition, one newborn was died among the khat chewer mothers, which accounts for 
$6.7 \%$ of the dead newborns. Similarly, one newborn with perinatal asphyxia was died among the mothers who had a history of alcohol intake, which accounts for $6.7 \%$ of the dead newborns with perinatal asphyxia (Table 1). 
Table 1

Socio-demographic characteristics of mothers of the newborn with perinatal asphyxia

\begin{tabular}{|c|c|c|c|}
\hline \multirow[t]{3}{*}{ Variables } & \multirow[t]{3}{*}{ Category } & \multicolumn{2}{|c|}{ Status of the newborn } \\
\hline & & Died & Survived \\
\hline & & $\mathrm{n}(\%)$ & $\mathrm{n}(\%)$ \\
\hline \multirow[t]{2}{*}{ Sex } & Male & $18(60 \%)$ & $324(61.4 \%)$ \\
\hline & Female & $18(40 \%)$ & $204(38.6 \%)$ \\
\hline \multirow[t]{3}{*}{ Maternal age } & $<20$ & $9(20 \%)$ & $69(13.1 \%)$ \\
\hline & $20-34$ & $15(33.3 \%)$ & $390(73.9 \%)$ \\
\hline & $>35$ & $21(46.7 \%)$ & $69(13.1 \%)$ \\
\hline \multirow[t]{2}{*}{ Marital status } & Not married & $30(66.7 \%)$ & $21(4.0 \%)$ \\
\hline & Married & $15(33.3 \%)$ & $507(96.0 \%)$ \\
\hline \multirow[t]{4}{*}{ Religion } & Orthodox & $21(46.7 \%)$ & $228(43.2 \%)$ \\
\hline & Muslim & $6(13.3 \%)$ & $105(19.9 \%)$ \\
\hline & Protestant & $18(40.0 \%)$ & $165(31.3 \%)$ \\
\hline & Others & $0(0.00 \%)$ & $30(5.7 \%)$ \\
\hline \multirow[t]{5}{*}{ Educational status of the mother } & Unable to read and write & $9(20.0 \%)$ & $54(10.2 \%)$ \\
\hline & Able to read and write & $12(26.7 \%)$ & $105(19.9 \%)$ \\
\hline & Grade 1-8 & $9(20.0 \%)$ & $207(39.2 \%)$ \\
\hline & Grade $9-12$ & $9(20.0 \%)$ & $105(19.9 \%)$ \\
\hline & College and above & $6(13.3 \%)$ & $57(10.8 \%)$ \\
\hline \multirow[t]{5}{*}{ Occupational status of the mother } & House wife & $9(20.0 \%)$ & $42(8.0 \%)$ \\
\hline & Self-employee & $12(26.7 \%)$ & $120(22.7 \%)$ \\
\hline & Farmers & $9(20.0 \%)$ & 198(37.5\%) \\
\hline & Merchant & $9(20.0 \%)$ & $117(22.2 \%)$ \\
\hline & Civil servant & $6(13.3 \%)$ & $51(9.7 \%)$ \\
\hline \multirow[t]{3}{*}{ Family size } & $<4$ & $9(20.0 \%)$ & $264(50.0 \%)$ \\
\hline & $4-6$ & 15(33.3\%) & 177(33.5\%) \\
\hline & $>6$ & $21(46.7 \%)$ & $87(16.5 \%)$ \\
\hline Place of residence & Urban & $15(33.3 \%)$ & $423(80.1 \%)$ \\
\hline
\end{tabular}




\begin{tabular}{|llll|}
\hline Distance b/n home and hospital & Rural & $30(66.7 \%)$ & $105(19.9 \%)$ \\
\cline { 2 - 4 } & $<10 \mathrm{~km}$ & $9(20.0 \%)$ & $357(67.6 \%)$ \\
\cline { 2 - 4 } & $10-50 \mathrm{~km}$ & $12(26.7 \%)$ & $102(19.3 \%)$ \\
\hline Estimated monthly income (ETB) & $>50 \mathrm{~km}$ & $69(13.1 \%)$ & $24(53.3 \%)$ \\
\cline { 2 - 4 } & $<1399$ & $18(40.0 \%)$ & $36(6.8 \%)$ \\
\hline & $1400-1999$ & $9(20.0 \%)$ & $114(21.6 \%)$ \\
\hline & $>2000-2599$ & $9(20.0 \%)$ & $189(35.8 \%)$ \\
\hline
\end{tabular}

\section{Obstetric related characteristics}

In this study, $81(14.1 \%)$ of the mothers had no antenatal visits. In addition; $207(36.1 \%), 87(15.2 \%)$, $78(13.6 \%)$, and $120(20.9 \%)$ of the mothers had one, two, three, and four antenatal visits, respectively. In considering gravidity and parity, $177(30.9 \%)$ of the mothers were primigravids for this birth and nearly one fourth $(25.7 \%)$ of the mothers were primiparous.

Regarding the number of pervaginal examinations, $351(61.3 \%)$ of the mothers had one to three pervagninal examinations. Nearly one fifths (19.9\%) of the newborns had a meconium-stained amniotic fluid. Among the respondents, 465(81.2\%), 60(10.5\%), 114(19.9\%), $129(22.5 \%)$ and $120(2.9 \%)$ of the newborn's mother faced the spontaneous onset of labor, obstructed labor, prolonged labor, PROM, and prolonged rupture of membranes, respectively.

Nearly one fifths $(21.5 \%)$ of the newborns were delivered at the health center. Among those who were delivered from the health center, 33(71.3\%) were died. In considering complications during delivery, $102(17.8 \%)$ of the newborns with perinatal asphyxia had cord prolapse, and $129(22.5 \%)$ of the newborns present with breech presentation. In addition, 408(71.2\%), 117(20.4\%), and 48(8.4) of the newborns were delivered by SVD and assisted instrumental and cesarean sections, respectively (Table 2). 
Table 2

Obstetric related characteristics of the newborns with perinatal asphyxia

\begin{tabular}{|c|c|c|c|}
\hline \multirow[t]{3}{*}{ Variables } & \multirow[t]{3}{*}{ Category } & \multicolumn{2}{|c|}{ Status of the newborn } \\
\hline & & Died & Survived \\
\hline & & $\mathrm{n}(\%)$ & $\mathrm{n}(\%)$ \\
\hline \multirow[t]{5}{*}{ Number of ANC visits } & No & $18(60.0 \%)$ & $54(10.2 \%)$ \\
\hline & One & $9(20.0 \%)$ & $198(37.5 \%)$ \\
\hline & Two & $3(6.7 \%)$ & $84(15.9 \%)$ \\
\hline & Three & $3(6.7 \%)$ & $75(14.2 \%)$ \\
\hline & Four and above & $3(6.7 \%)$ & $117(22.2 \%)$ \\
\hline \multirow[t]{2}{*}{ Gravidity } & Primigravida & $6(13.3 \%)$ & $171(32.4 \%)$ \\
\hline & Multigravida & $39(86.7 \%)$ & $357(67.6 \%)$ \\
\hline \multirow[t]{3}{*}{ Parity } & Primipara & $3(6.7 \%)$ & $144(27.3 \%)$ \\
\hline & $2-4$ birth & $15(33.3 \%)$ & $159(30.1 \%)$ \\
\hline & Five and above births & $27(60.0 \%)$ & $225(42.6 \%)$ \\
\hline \multirow[t]{2}{*}{ Number of pervaginal examinations } & $1-3$ & $21(46.7 \%)$ & $330(62.5 \%)$ \\
\hline & Four and above & $24(53.3 \%)$ & $198(37.5 \%)$ \\
\hline \multirow{2}{*}{$\begin{array}{l}\text { History of Meconium stained amniotic } \\
\text { fluid }\end{array}$} & Yes & $36(80.0 \%)$ & $78(14.8 \%)$ \\
\hline & No & $9(20.0 \%)$ & $450(85.2 \%)$ \\
\hline \multirow[t]{2}{*}{ Onset of labor } & Spontaneous & $36(80.0 \%)$ & $429(81.3 \%)$ \\
\hline & Induced & $9(20.0 \%)$ & $99(18.8 \%)$ \\
\hline \multirow[t]{2}{*}{ Antepartum hemorrhage } & Yes & $12(26.7 \%)$ & $120(22.7 \%)$ \\
\hline & No & $33(73.3 \%)$ & $408(77.3 \%)$ \\
\hline \multirow[t]{2}{*}{ Obstructed labor } & Yes & $18(60.0 \%)$ & $33(6.3 \%)$ \\
\hline & No & $18(40.0 \%)$ & $495(93.8 \%)$ \\
\hline \multirow[t]{2}{*}{ Duration of labor (hrs) } & Less than 18 & $33(73.3 \%)$ & $81(15.3 \%)$ \\
\hline & Greater than 18 & $12(26.7 \%)$ & $447(84.7 \%)$ \\
\hline \multirow[t]{2}{*}{ Premature rupture of membrane } & Yes & $30(66.7 \%)$ & $99(18.8 \%)$ \\
\hline & No & $15(33.3 \%)$ & $429(81.3 \%)$ \\
\hline Prolonged rupture of membrane & Yes & $33(73.3 \%)$ & $87(16.5 \%)$ \\
\hline
\end{tabular}




\begin{tabular}{|llll|}
\hline \multirow{2}{*}{ Cord prolapse } & No & $12(26.7 \%)$ & $441(83.5 \%)$ \\
\hline Presentation & Yes & $33(73.3 \%)$ & $63(13.1 \%)$ \\
\cline { 2 - 4 } & No & $12(26.7 \%)$ & $459(86.7 \%)$ \\
\hline Mode of delivery & Cephalic & $15(33.3 \%)$ & $429(81.3 \%)$ \\
\cline { 2 - 4 } & Breech & $30(66.7 \%)$ & $99(18.8 \%)$ \\
\hline Spontaneous vaginal & $18(40.0 \%)$ & $390(73.9 \%)$ \\
\hline delivery & & \\
\cline { 2 - 4 } & Assisted instrumental & $21(46.7 \%)$ & $96(18.2 \%)$ \\
\cline { 2 - 4 } & Cesarean section & $6(13.3 \%)$ & $42(8.0 \%)$ \\
\hline$<37$ & $12(26.7 \%)$ & $279(52.8 \%)$ \\
\hline $37-42$ & $12(26.7 \%)$ & $198(37.5 \%)$ \\
\hline$>42$ & $21(46.75)$ & $51(9.7 \%)$ \\
\hline
\end{tabular}

\section{Newborn related characteristics and Medical related characteristics of the mother}

Nearly half (50.8\%) of the newborns were delivered at gestational age, less than 37 weeks and $72(12.6 \%)$ of them were post terms (gestational age more than 42 weeks). In this study, a total of 573 newborns had a first minute APGAR score of three or less. All of the newborns were resuscitated at birth and $471(82.2 \%)$ of the newborns did not cry during birth. Considering the birth weight, $186(32.5 \%)$ of the newborns had a birth weight less than 2500 grams, of which 30 newborns died, which accounts for $66.7 \%$ of the dead newborns. Twenty-one (3.7\%) of the admitted newborns had at least one spot of convulsion or spasm.

Pregnancy induced hypertension (PIH), maternal iron deficiency anemia; maternal diabetes mellitus (DM) and maternal HIV status were the identified health problems affecting the survival status of newborns with perinatal asphyxia. In this study, $165(28.8 \%), 105(18.3 \%), 18(3.1 \%)$ and $30(5.2 \%)$ of the mothers had a history of diagnosed PIH, iron deficiency anemia, DM and HIV respectively (Table 3). 
Table 3

Newborn related and maternal medical disorders affecting the survival status of the newborns with perinatal asphyxia

\begin{tabular}{|c|c|c|c|}
\hline \multirow[t]{3}{*}{ Variable } & \multirow[t]{3}{*}{ Category } & \multicolumn{2}{|c|}{ Status of the newborn } \\
\hline & & Died & Survived \\
\hline & & $n(\%)$ & $n(\%)$ \\
\hline \multirow[t]{2}{*}{ Cry immediately at birth } & Yes & $3(6.7 \%)$ & $99(18.8 \% \%)$ \\
\hline & No & $42(93.3 \%)$ & $429(81.3 \%)$ \\
\hline \multirow[t]{2}{*}{ History of convulsion or spasm } & Yes & $12(26.7 \%)$ & $9(1.7 \%)$ \\
\hline & No & $33(73.3 \%)$ & $519(98.3 \%)$ \\
\hline \multirow[t]{2}{*}{ Birth weight (gram) } & $<2500$ & $30(66.7 \%)$ & $156(29.5 \%)$ \\
\hline & $\geq 2500$ & 15(33.3\%) & $372(70.5 \%)$ \\
\hline \multirow[t]{2}{*}{ Pregnancy induced hypertension } & Yes & $36(80.0 \%)$ & $129(24.4 \%)$ \\
\hline & No & $9(20.0 \%)$ & $399(75.6 \%)$ \\
\hline \multirow[t]{2}{*}{ Maternal Iron deficiency anemia } & Yes & $24(53.3 \%)$ & $81(15.3 \%)$ \\
\hline & No & $21(46.7 \%)$ & $447(84.7 \%)$ \\
\hline \multirow[t]{2}{*}{ Maternal Diabetes mellitus } & Yes & $3(6.7 \%)$ & $15(2.8 \%)$ \\
\hline & No & $42(93.3 \%)$ & $513(97.2 \%)$ \\
\hline \multirow[t]{2}{*}{ HIV status } & Positive & $3(6.7 \%)$ & $27(5.1 \%)$ \\
\hline & Negative & 42(93.3\%) & $501(94.9 \%)$ \\
\hline
\end{tabular}

\section{The survival status of newborns with perinatal asphyxia}

The cumulative proportion of survival among the newborns admitted with perinatal asphyxia was $95.21 \%$ $(95 \% \mathrm{Cl}: 91.00,97.48)$ at the end of the first follow-up day. In addition, it was $92.82 \%(95 \% \mathrm{Cl}: 87.95$, 95.77), $92.02 \%(95 \% \mathrm{Cl}: 86.84,95.22)$ and $90.78 \%(95 \% \mathrm{Cl}: 84.82,94.48)$ at the end of the second, third, and fourth follow-up days respectively. As we have seen from Fig. 2, there was a rapid decline of survival on the first day and it became slow in the corresponding follow-up days. The overall mean survival time was 6.55 (95\% Cl: 6.33, 6.77) (Fig. 2).

Among newborns admitted with perinatal asphyxia 27 (4.71\%) died in the first follow up day, which is $60 \%$ of the observed deaths within the study period. Similarly, the proportion of death at the second and third follow-up days was $2.09 \%$ and $0.52 \%$ respectively. There was no observed death after the fourth follow-up. In this study, $45(7.85 \%)$ of the newborns with perinatal asphyxia died and $531(92.15 \%)$ were recovered (Fig. 3). 


\section{Log rank estimate of the covariates of variables}

The Kaplan Meier survival curve together with the log-rank test estimates the chi square and $p$-value of each variable. Distance between home and hospital, referral status of the newborn, meconium-stained amniotic fluid, obstructed labor, premature rupture of membrane, prolonged rupture of membrane, cord prolapse, presentation, place of delivery, mode of delivery, history of convulsion or spasm, birth weight, pregnancy-induced hypertension, and iron deficiency anemia were candidate variables for multivariable analysis in cox proportional hazard model (Table 4). 
Table 4

The log rank estimate of the variables determining the survival status among newborns admitted with perinatal asphyxia

\begin{tabular}{|c|c|c|}
\hline \multirow[t]{2}{*}{ Variables } & \multicolumn{2}{|c|}{ Log rank estimate } \\
\hline & Chi square $\left(X^{2}\right)$ & P-value \\
\hline Sex & 0.003 & 0.959 \\
\hline Maternal age & 1.365 & 0.81 \\
\hline Marital status & 3.85 & 0.64 \\
\hline Religion & 1.48 & 0.68 \\
\hline Educational status of the mother & 2.97 & 0.56 \\
\hline Occupational status of the mother & 3.73 & 0.44 \\
\hline Family size & 2.21 & 0.310 \\
\hline Place of residence & 1.79 & 0.32 \\
\hline Distance between home and hospital & 20.05 & 0.0001 \\
\hline Referral status & 26.02 & 0.0001 \\
\hline Estimated monthly income (ETB) & 1.89 & 0.53 \\
\hline Maternal Khat chewing status & 0.089 & 0.765 \\
\hline Alcohol intake & 0.031 & 0.86 \\
\hline Number of ANC visits & 3.09 & 0.74 \\
\hline Gravidity & 2.31 & 0.129 \\
\hline Parity & 3.27 & 0.194 \\
\hline Number of pervaginal examinations & 1.43 & 0.23 \\
\hline Meconium stained amniotic fluid & 37.04 & 0.0001 \\
\hline Onset of labor & 0.005 & 0.94 \\
\hline Antepartum hemorrhage & 0.134 & 0.715 \\
\hline Obstructed labor & 43.79 & 0.0001 \\
\hline Duration of labor & 5.43 & 0.631 \\
\hline Premature rupture of membrane & 17.9 & 0.0001 \\
\hline Prolonged rupture of membrane & 28.35 & 0.0001 \\
\hline Cord prolapse & 35.44 & 0.0001 \\
\hline
\end{tabular}




\begin{tabular}{|lll|}
\hline Variables & \multicolumn{2}{l|}{ Log rank estimate } \\
\hline Presentation & 18.40 & 0.0001 \\
\hline Place of delivery & 26.02 & 0.0001 \\
\hline Mode of delivery & 8.36 & 0.015 \\
\hline Gestational age & 0.48 & 0.487 \\
\hline Cry immediately at birth & 1.38 & 0.239 \\
\hline History of convulsion or spasm & 26.32 & 0.0001 \\
\hline Birth weight(gram) & 8.94 & 0.003 \\
\hline Pregnancy induced hypertension & 21.12 & 0.0001 \\
\hline Maternal Iron deficiency anemia & 13.15 & 0.0001 \\
\hline Maternal Diabetes mellitus & 0.733 & 0.392 \\
\hline Maternal HIV status & 0.07 & 0.79 \\
\hline SUrVival time among the Covariates of predictors
\end{tabular}

The mean survival time was different among the covariates of each predictor. The mean survival time was higher among the newborns that had no cord prolapse as compared with those who had cord prolapse during delivery. Similarly, the average survival time was higher among newborns born with a mother who had no pregnancy-induced hypertension and no diagnosed iron deficiency anemia as compared with those with pregnancy-induced hypertension and iron deficiency anemia respectively (Table 5). 
Table 5

The mean survival time estimate of the newborns with perinatal asphyxia among the covariates of predictors

\begin{tabular}{|c|c|c|}
\hline Variables & Category & Mean survival time $(95 \% \mathrm{Cl})$ \\
\hline \multirow[t]{2}{*}{ Cord prolapse } & Yes & $5.19(4.31,6.07)$ \\
\hline & No & $6.85(6.70,6.99)$ \\
\hline \multirow[t]{2}{*}{ Pregnancy induced hypertension } & Yes & $5.76(5.14,6.38)$ \\
\hline & No & $6.87(6.73,7.01)$ \\
\hline \multirow[t]{2}{*}{ Iron deficiency anemia } & Yes & $5.72(4.94,6.50)$ \\
\hline & No & $6.74(6.56,6.93)$ \\
\hline \multirow[t]{2}{*}{ Convulsion or spasm } & Yes & $3.04(2.07,4.02)$ \\
\hline & No & $6.65(6.45,6.85)$ \\
\hline
\end{tabular}

In this study, cord prolapse, pregnancy induced hypertension, iron deficiency anemia of the mother and having a history of convulsion or spasm of the newborn were statistically significant in the multivariable cox regression model.

Newborns having cord prolapse during delivery had six times higher risk of mortality as compared with those who had no cord prolapse (AHR: $6.5 ; 95 \% \mathrm{Cl}: 1.18,36.01)$. The risk of mortality among newborns with perinatal asphyxia and delivered with mothers who had a history of pregnancy induced hypertension was 25 times higher as compared with those who had no pregnancy induced hypertension (AHR: 25.4; $95 \% \mathrm{Cl}: 3.68,175.0)$.

Newborns with perinatal asphyxia and delivered with mothers with iron deficiency anemia had five times higher risk mortality as compared with those mothers who had no iron deficiency anemia (AHR: 5.9; $95 \%$ Cl: $1.19,29.5)$. Newborns admitted with perinatal asphyxia and had history of convulsion or spasm had 10 times higher risk of mortality as compared with those who had no history of convulsion of spasm (AHR: $10.23 ; 95 \% \mathrm{Cl}: 2.24,46.54$ )(Table 6). 
Table 6

Predictors of mortality among newborns admitted with perinatal asphyxia.

\begin{tabular}{|c|c|c|c|c|c|}
\hline \multirow[t]{2}{*}{ Variables } & \multirow[t]{2}{*}{ Category } & \multicolumn{2}{|c|}{ Status } & \multirow[t]{2}{*}{$\operatorname{COR}(95 \% \mathrm{Cl})$} & \multirow[t]{2}{*}{$\mathrm{AOR}(95 \% \mathrm{Cl})$} \\
\hline & & Died & Survived & & \\
\hline \multirow{3}{*}{$\begin{array}{l}\text { Distance b/n home and } \\
\text { hospital }\end{array}$} & $<10 \mathrm{~km}$ & 3 & 119 & 1 & 1 \\
\hline & $10-50 \mathrm{~km}$ & 4 & 34 & $\begin{array}{l}4.26(0.95 \\
19.04)\end{array}$ & $\begin{array}{l}0.24(0.01 \\
5.36)\end{array}$ \\
\hline & $>50 \mathrm{~km}$ & 23 & 8 & $\begin{array}{l}11.53(3.04 \\
43.65)^{\star}\end{array}$ & $\begin{array}{l}0.18(0.007 \\
5.01)\end{array}$ \\
\hline \multirow[t]{2}{*}{ Referral status } & Yes & 11 & 30 & $\begin{array}{l}\text { 10.52(3.34 } \\
33.05)^{\star}\end{array}$ & $\begin{array}{l}0.65(0.02 \\
16.62)\end{array}$ \\
\hline & No & 4 & 146 & 1 & 1 \\
\hline \multirow[t]{2}{*}{$\begin{array}{l}\text { Meconium stained } \\
\text { amniotic fluid }\end{array}$} & Yes & 12 & 26 & $\begin{array}{l}\text { 16.95(4.78 } \\
60.12)^{\star}\end{array}$ & $\begin{array}{l}1.46(0.17 \\
12.24)\end{array}$ \\
\hline & No & 3 & 150 & 1 & 1 \\
\hline \multirow[t]{2}{*}{ Obstructed labor } & Yes & 9 & 11 & $\begin{array}{l}\text { 13.76(4.89 } \\
38.69)^{\star}\end{array}$ & $\begin{array}{l}0.48(0.02 \\
7.87)\end{array}$ \\
\hline & No & 6 & 165 & 1 & 1 \\
\hline \multirow[t]{2}{*}{ Premature ROM } & Yes & 10 & 33 & $\begin{array}{l}7.08(2.42 \\
20.72)^{\star}\end{array}$ & $\begin{array}{l}1.54(0.20 \\
11.90)\end{array}$ \\
\hline & No & 5 & 143 & 1 & 1 \\
\hline \multirow[t]{2}{*}{ Prolonged ROM } & Yes & 11 & 29 & $\begin{array}{l}\text { 11.34(3.60 } \\
35.70)^{\star}\end{array}$ & $\begin{array}{l}0.50(0.02 \\
10.84)\end{array}$ \\
\hline & No & 4 & 147 & 1 & 1 \\
\hline \multirow[t]{2}{*}{ Cord prolapse } & Yes & 11 & 23 & $\begin{array}{l}\text { 13.68(4.35, } \\
43.02)^{\star}\end{array}$ & $\begin{array}{l}6.5(1.18 \\
36.01)^{\star \star}\end{array}$ \\
\hline & No & 4 & 153 & 1 & 1 \\
\hline \multirow[t]{2}{*}{ Presentation } & Cephalic & 5 & 143 & 1 & 1 \\
\hline & Breech & 10 & 33 & $\begin{array}{l}7.22(2.46 \\
21.14)^{\star}\end{array}$ & $\begin{array}{l}4.1(0.91 \\
18.54)\end{array}$ \\
\hline \multirow[t]{2}{*}{ Place of delivery } & Health center & 11 & 30 & $\begin{array}{l}\text { 10.52(3.34 } \\
33.05)^{\star}\end{array}$ & $\begin{array}{l}6.4(0.73 \\
6.82)\end{array}$ \\
\hline & Hospital & 4 & 146 & 1 & 1 \\
\hline Birth weight(gram) & $<2500$ & 10 & 52 & $\begin{array}{l}2.09(1.22 \\
3.58)^{\star}\end{array}$ & $\begin{array}{l}2.99(0.73 \\
12.13)\end{array}$ \\
\hline
\end{tabular}




\begin{tabular}{|c|c|c|c|c|c|}
\hline \multirow[t]{2}{*}{ Variables } & \multirow[t]{2}{*}{ Category } & \multicolumn{2}{|c|}{ Status } & \multirow[t]{2}{*}{$\operatorname{coR}(95 \% \mathrm{Cl})$} & \multirow[t]{2}{*}{ AOR(95\%Cl) } \\
\hline & & Died & Survived & & \\
\hline & $>2500$ & 5 & 124 & 1 & 1 \\
\hline \multirow[t]{2}{*}{$\begin{array}{l}\text { Pregnancy induced } \\
\text { hypertension }\end{array}$} & Yes & 12 & 43 & $\begin{array}{l}3.23(1.71 \\
6.09)^{\star}\end{array}$ & $\begin{array}{l}\text { 25.4(3.68, } \\
175.0)^{\star \star}\end{array}$ \\
\hline & No & 3 & 133 & 1 & 1 \\
\hline \multirow[t]{2}{*}{$\begin{array}{l}\text { Maternal Iron deficiency } \\
\text { anemia }\end{array}$} & Yes & 8 & 27 & $\begin{array}{l}2.28(1.37 \\
3.79)^{\star}\end{array}$ & $\begin{array}{l}5.9(1.19 \\
29.5)^{\star \star}\end{array}$ \\
\hline & No & 7 & 149 & 1 & 1 \\
\hline \multirow[t]{3}{*}{ Mode of delivery } & SVD & 6 & 130 & 1 & 1 \\
\hline & $\begin{array}{l}\text { Assisted } \\
\text { instrumental }\end{array}$ & 7 & 32 & $\begin{array}{l}4.2(1.4 \\
12.65)^{\star}\end{array}$ & $\begin{array}{l}0.87(0.15 \\
5.12)\end{array}$ \\
\hline & CS & 2 & 14 & $\begin{array}{l}2.96(0.59 \\
14.70)\end{array}$ & $\begin{array}{l}5.86(0.84 \\
40.77)\end{array}$ \\
\hline \multirow[t]{2}{*}{ Convulsion } & Yes & 4 & 3 & $\begin{array}{l}3.27(1.84 \\
5.82)^{\star}\end{array}$ & $\begin{array}{l}10.23(2.24 \\
46.54)^{\star \star}\end{array}$ \\
\hline & No & 11 & 173 & 1 & 1 \\
\hline
\end{tabular}

\section{Discussion}

This study assesses the predictors of mortality among newborns admitted with perinatal asphyxia at public hospitals in Southern Ethiopia and it showed there was a high proportion of mortality at the early admission periods especially at the first day and gradually declines as the follow-up period has been increased.

Newborns having cord prolapse during delivery had six times higher risk of mortality as compared with those who had no cord prolapse (AHR: $6.5 ; 95 \% \mathrm{Cl}: 1.18,36.01$ ). This study finding is similar with the study conducted in Karachi, Pakistan (2). The principal causes of perinatal asphyxia in this context was thought to be cord compression and umbilical arterial vasospasm which prevents venous and arterial blood flow to and from the fetus. In addition; it can predispose other factors that lead the newborn to die such as assisted ventilation requirement, low cord $\mathrm{pH}$, meconium aspiration, hyaline membrane disease, convulsion, neonatal encephalopathy, and cerebral palsy $(16,17)$.

Consistent with the study conducted at Dilla University referral hospital, Southern Ethiopia, Tigray regional state, Ethiopia and tertiary care center in Ahmedabad, Gujarat, India and Ayder comprehensive specialized hospital, Northern Ethiopia $(18,19,20,21)$, the risk of mortality among newborns with 
perinatal asphyxia and delivered with mothers who had a history of pregnancy induced hypertension was 25 times higher as compared with those who had no pregnancy-induced hypertension (AHR: $25.4 ; 95 \% \mathrm{Cl}$ : $3.68,175.0)$. This might be related to the effect of diminished uteroplacental blood flow and placental ischemia, which can be due to pregnancy-induced hypertension which reduces blood flow to the fetus (22, 23). In addition; pregnancy-induced hypertension $(\mathrm{PIH})$ has an effect on the reduction of blood supply, nutrients, and oxygen to the fetus at intrauterine life, finally which ends up in intrauterine growth restriction. This condition can contribute to newborn mortality with perinatal asphyxia (24).

Newborns with perinatal asphyxia and delivered by mothers who have iron deficiency anemia had five times higher risk mortality as compared with the counterparts who had no iron deficiency anemia (AHR: $5.9 ; 95 \% \mathrm{Cl}: 1.19,29.5)$. This study finding is concise with the study done at Dilla University referral hospital, Southern Ethiopia, Southern Nations Nationalities and Peoples Regional State of Ethiopia and Jimma Zone, Southwest Ethiopia $(16,25,26)$.

Newborns admitted with perinatal asphyxia and had a history of convulsion of spasm had a 10 times higher risk of mortality as compared with those who had no history of convulsion of spasm (AHR: 10.23; $95 \% \mathrm{Cl}: 2.24,46.54)$. The possible reason might be convulsion that may cause the newborn to cease breathing (apnea). If this interruption in breathing persists, it can result in a decline in oxygen saturation in the blood to a life-threatening level.

Irrespective of the study conducted at Southern Nepal, Ayder comprehensive specialized hospital, Dilla University referral hospital, primiparity, place of delivery, multi-parity, low birth weight, mode of delivery and premature rupture of the membrane was not statistically significant predictors of mortality $(18,27$, 28).

\section{Limitation of the study}

Since the study was conducted among the newborns delivered at public hospitals, it cannot be generalized for the newborns delivered at home, health centers and health posts. In addition, this study did not assess the complications secondary to perinatal asphyxia.

\section{Conclusion}

The survival status of newborns admitted with perinatal asphyxia was low at the early follow up periods after admission to the hospital and the risk of mortality was decreased at the later follow up periods and having cord prolapse of the newborn during delivery, maternal history of pregnancy-induced hypertension, maternal history of iron deficiency anemia and newborn history of convulsion or spasm were the independent predictors of mortality.

\section{Abbreviations}

ANC Antenatal Care 
APGAR Appearance, pulse, Grimmace, Activity and Respiratory effort

APH Antepartum hemorrhage

DM Diabetes mellitus

PIH Pregnancy induced hypertension

WHO World Health Organization

\section{Declarations}

\section{Consent for publication}

Not applicable

\section{Availability of data and materials}

The data sets generated and/or analyzed are available with a reasonable request through the corresponding author.

\section{Competing interest}

I declare that the authors have no any conflict of interest.

\section{Funding}

Not applicable

\section{Author's contribution}

All authors made a significant contribution to the work reported, whether that is in the conception, study design, execution, acquisition of data, analysis and interpretation, or in all these areas; took part in drafting, revising or critically reviewing the article; gave final approval of the version to be published; have agreed on the journal to which the article has been submitted; and agree to be accountable for all aspects of the work.

\section{Acknowledgements}

We would like to thank the mothers who are directly involved in the study and administrator of each hospital for their effort and permission to conduct the study. 


\section{References}

1. Pitsawong C, Panichkul P. Risk factors associated with birth asphyxia in Phramongkutklao Hospital. Thai J Obstet Gynaecol. 2012;19(4):165-71.

2. Ekwochi U, Asinobi NI, Osuorah CDI, Ndu IK, Ifediora C, Amadi OF, et al. Incidence and predictors of perinatal asphyxia: A 4-year prospective study of newborns delivered in health care facilities in Enugu, South-West Nigera. Clinical medicine insights: Pediatrics. 2017; 11: 1-10.

3. Bryce J, Boschi-Pinto C, Shibuya K, Black RE. WHO estimates of the causes of death in children. Lancet. 2005;365(9465):1147-52.

4. World Health Organization. Newborns: reducing mortality. 2018. Available: https://www.who.int/newsroom/fact-sheet/detail, accessed on may 2,2018.

5. Joy Lawn PM. Simon Cousens.: Africa's newborns-counting them and making them count. Opportunities for Africa's Newborns 2010.

6. Birth Asphyxia -. Summary of the previous meeting and protocol overview [http:// .

7. State of the World's Children, UNICEF; 2009.

8. World Health Organization. GUIDELINE ON BASIC NEWBORN, RESUSCITATION. 2012. Available: https://www.who.int/maternal_child_adolescent/documents/basic_newborn_resuscitation/en, accessed on April 5,2018.

9. United Nations Children's Fund [UNICEF]. Maternal and Newborn Health Disparities in Ethiopia. COUNTRY PROFIE_ETH. 2015. Available: https://www.data.unicef.org accessed on January 03, 2018.

10. Federal Minstry of Health [Ethiopia]. Health Sector Transformation Plan (HSTP 2016-2020). Addis Ababa: $\mathrm{FMOH} ; 2015$.

11. Federal Minstry of Health [Ethiopia]. Neonatal Intensive Care Unit (NICU) Training: Management Protocol. Addis Ababa, Ethiopia; FMO, 2014.

12. Roberto A, Annalisa P, Maria DP. Perinatal asphyxia in the term newborn. Journal of Pediatric and Neonatal Individualized Medicine. 2014;3(2).

13. Kebede EB, Akuma AO, Tarfa YB. Perinatal Asphyxia among neonates admitted. Jimma Medical Center. 2020;7:1-5.

14. Desalew A, Sintayehu Y, Teferi N, et al. Cause and predictors of neonatal mortality among neonates admitted to neonatal intensive care units of public hospitals in eastern Ethiopia: a facility-based prospective follow-up study. BMC Pediatr. 2020;20:160.

15. Samuel D, Mesfin K, Feleke G, Tadele g. Predictors of neonatal mortality among neonates who admitted in Neonatal intensive care unit at Arba Minch general Hospital. Ethiopian Journal of Health Development. 2019;33(1):46-52.

16. Waleed ASA, Mostafa AH. Optimal management of umbilical cord prolapse. International Journal of Women's Health. 2018;10:459-65. 
17. Murphy DJ, Mackenzie I. The mortality and morbidity associated with umbilical cord prolapse. $\mathrm{Br} \mathrm{J}$ Obstet Gynaecol. 1995;102(10):826-30.

18. Abebe A, Getnet M, Gerezgiher BA, Ashenafi D. Prevalence and associated factors of perinatal asphyxia among newborns in Dilla University referral hospital, Southern Ethiopia- 2017. Pediatric Health Medicine Therapeutics. 2019;10:69-74.

19. Meghavini RP, Pradhyuman V. Effect of pregnancy induced hypertension on maternal and perinatal outcome at tertiary care center in Ahmedabad, Gujarat, India. International Journal of Reproduction Contraception Obstetrics Gynecology. 2017;6(10):4661-5.

20. Abadi KB, llesanmi AO, Christopher OA, Afework M. Effect of pregnancy induced hypertension on adverse perinatal outcomes in Tigray regional state, Ethiopia: a prospective cohort study. BMC Pregnancy Childbirth. 2020;20.

21. Gebrehiwot TG, Fikaden BH, T.A.Haftom. Prevalence and Associated Factors of Perinatal Asphyxia in Neonates Admitted to Ayder Comprehensive Specialized Hospital, Northern Ethiopia. Hindawi: International Journal of Pediatrics. 2020;2020.

22. Gilbert JS, Ryan MJ, LaMarca BB, Sedeek M, Murphy SR, Granger JP. Pathophysiology of hypertension during preeclampsia: linking placental ischemia with endothelial dysfunction. Am J Phys Heart Circ Phys. 2008;294(2):H541-H50.

23. George IO, Jeremiah I. Perinatal outcome of babies delivered to eclamptic mothers: a prospective study from a Nigerian tertiary hospital. Int J Biomed Sci. 2009;5(4):390.

24. Yodit ZB, Abel GK, Letekirstos G, Natnael EA, Lidya ZB, Sumeya AM, et al. Risk Factors of Birth Asphyxia Among Neonates Born in Public Hospitals of Tigray, Northern Ethiopia. Pediatric Health Med Ther. 2020;11:13-20.

25. Getachew B, Yifru B. Perinatal mortality and associated risk factors: a case control study. Ethiop J Health Sci. 2012;22(3).

26. Gurmesa T, Mesganaw F, Alemayehu W. Determinants and causes ofneonatal mortality in Jimma Zone, Southwest Ethiopia: a multilevel analysis of prospective follow up study. Plos one. 2014;9(9).

27. Anne CCL, Luke CM, James MT, Joanne K, Subarna KK, Steven CL, et al. Risk Factors for Neonatal Mortality due to Birth Asphyxia in Southern Nepal. Pediatrics. 2008;121(5):e1381-e90.

28. Abay W, Ayesheshim M, Christine SD. Birth asphyxia and its associated factors among newborns in public hospital, northeast Amhara, Ethiopia. PLoS ONE. 2019;14(12).

\section{Figures}




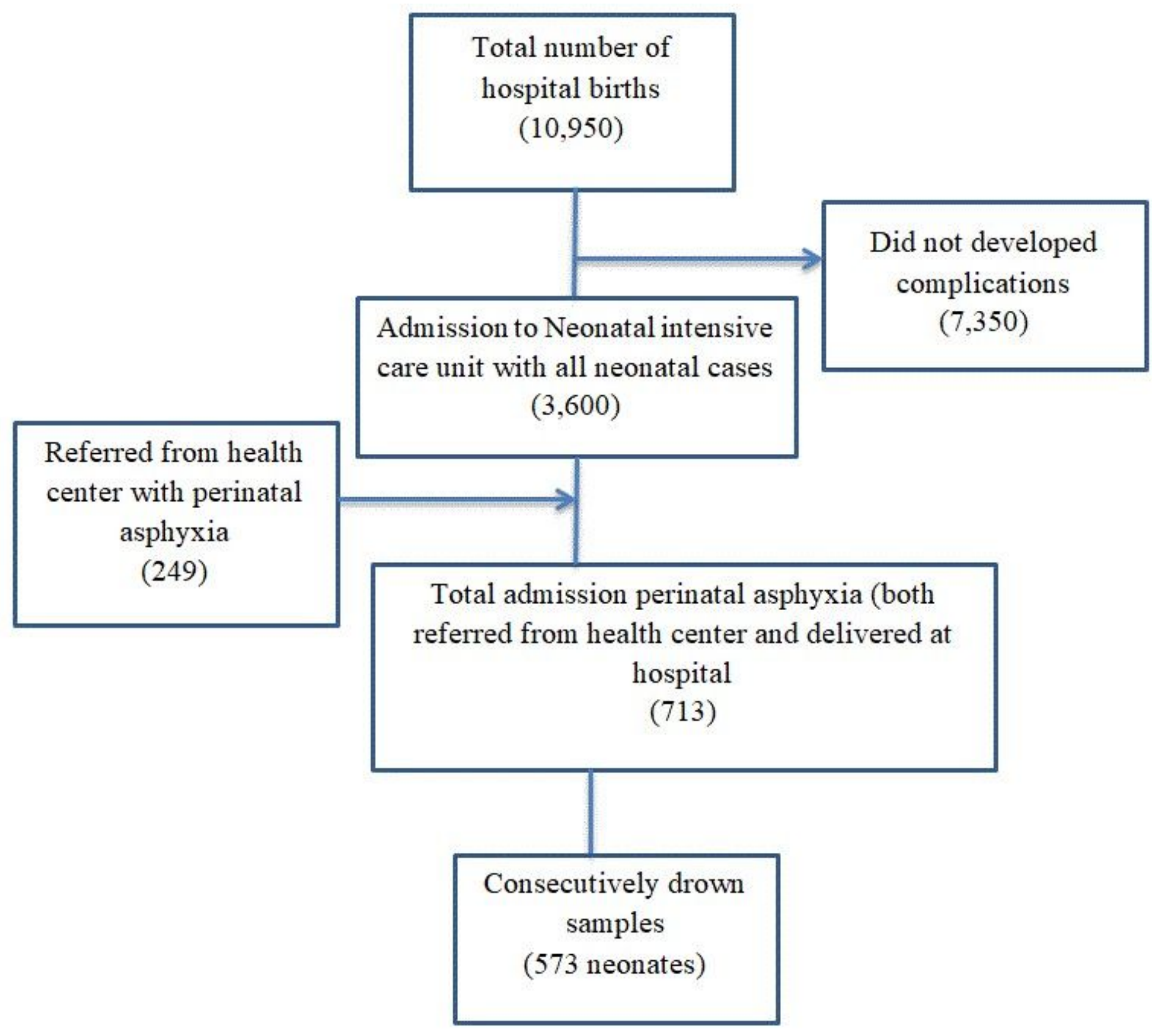

Figure 1

The schematic presentation of sampling procedure for the study on predictors of mortality among newborns presented with perinatal asphyxia at public hospitals at Southern Ethiopia. 


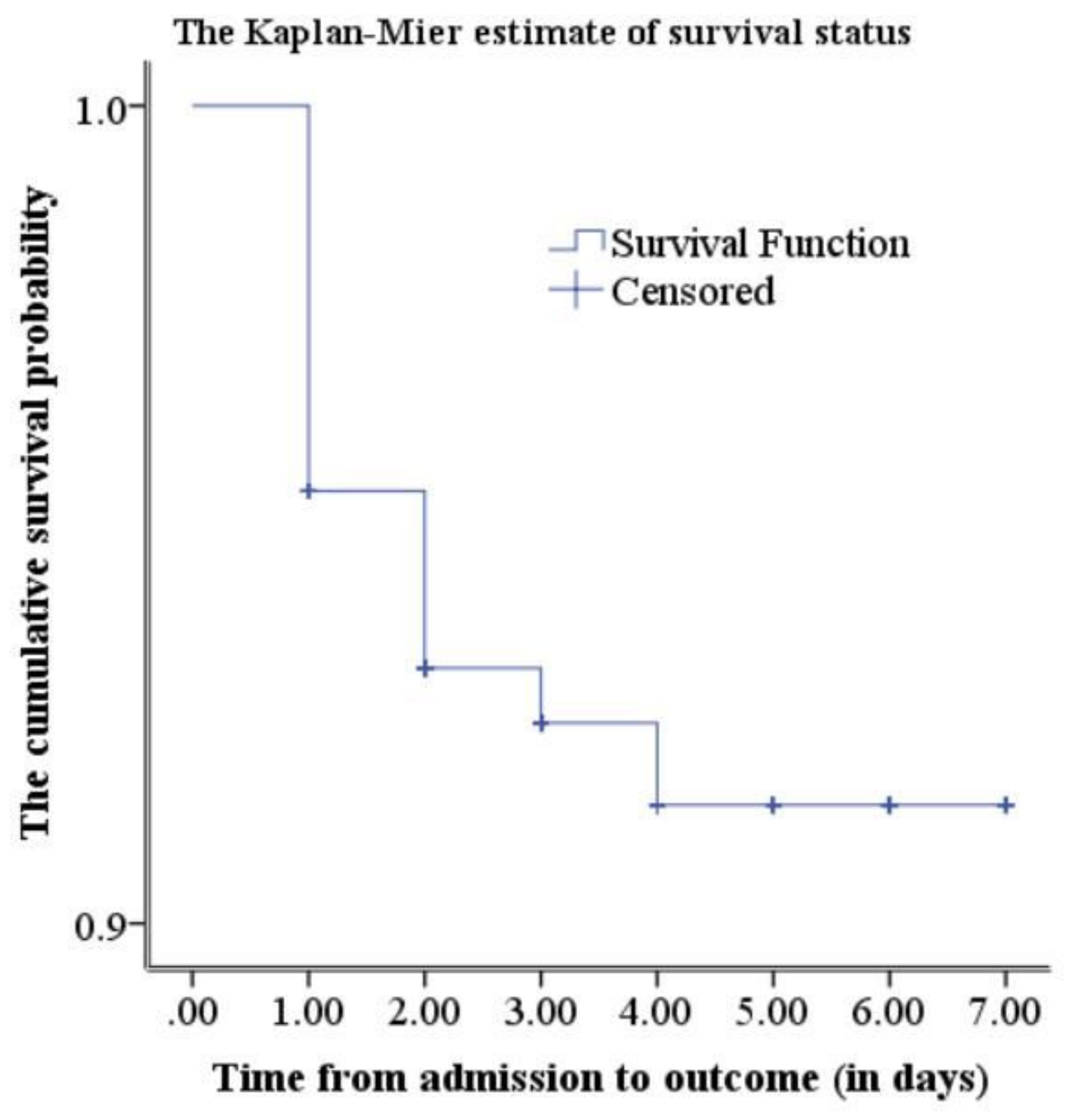

Figure 2

The Kaplan Meier estimate of the survival function among newborns admitted with perinatal asphyxia 
The Kaplan-Miere estimate of hazard of death

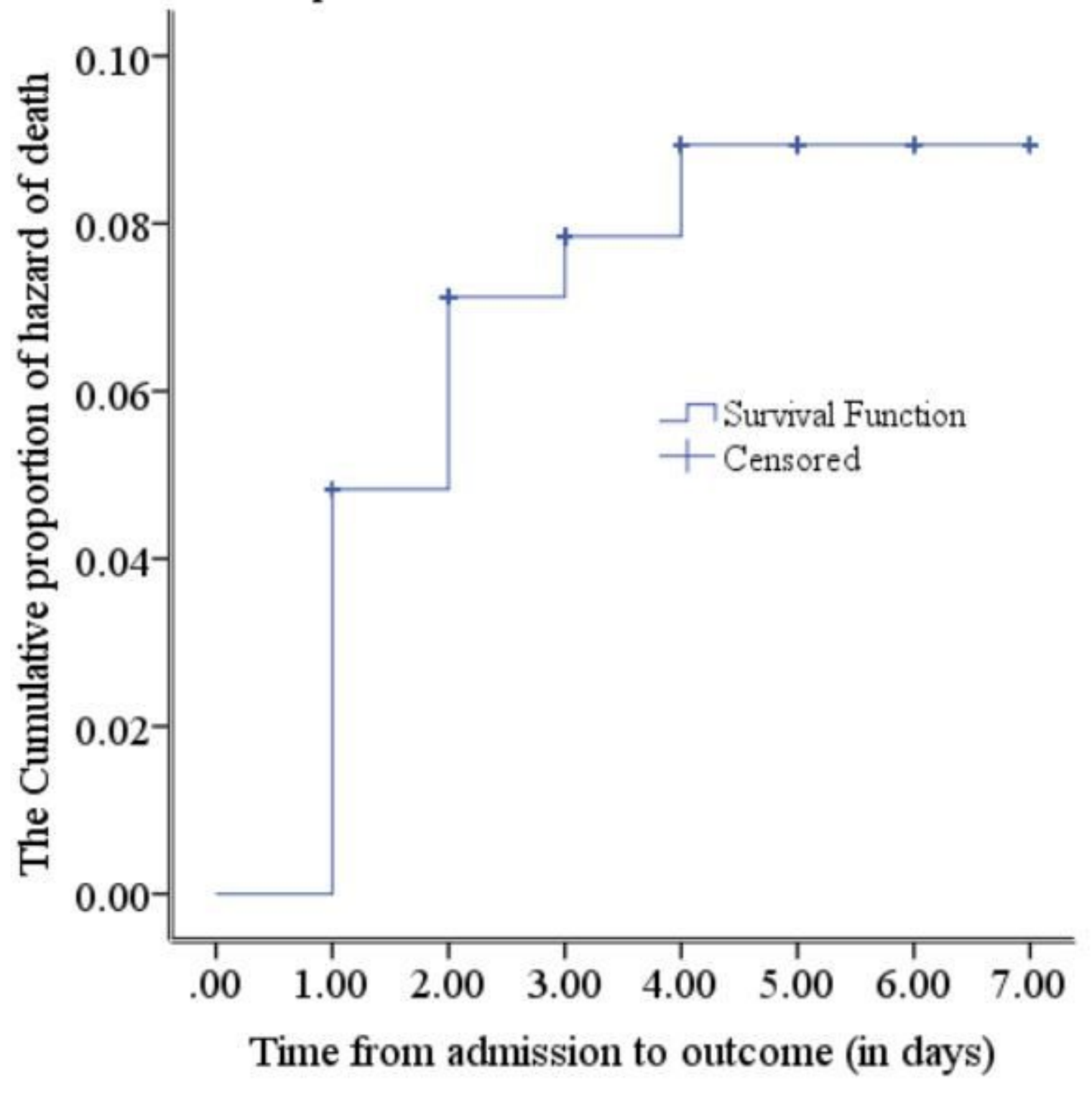

Figure 3

The Kaplan Meier estimate of hazard of death among newborns admitted with perinatal asphyxia 